\title{
Adherence to inhaler treatments in obstructive lung diseases: A different perspective
}

\author{
Funda Aksu ${ }^{1}$, Kurtuluş Aksu ${ }^{1}$, Tuğba Tezvergil ${ }^{1}$, and Ali Fırıncıŏluları ${ }^{1}$ \\ ${ }^{1}$ Atatürk Göğüs Hastalıkları Ve Göğüs Cerrahisi Eğitim Ve Araştırma Hastanesi
}

October 1, 2020

\begin{abstract}
Aim To evaluate the consistency of adherence information given to clinicians by patients with obstructive lung disease and their relatives. Methods A cross-sectional study was conducted in patients with asthma and chronic obstructive pulmonary disease (COPD). Patients and their relatives were independently questioned about the patients' adherence to inhaler therapy. The consistency of the information given by the patients and their relatives in terms of patient's adherence to the inhaler treatment was evaluated. Results Sixty-six patients, 42 followed up with a diagnosis of COPD, 24 with a diagnosis of asthma were included in the study. According to the patients' own statements, the number of patients who regularly used the prescribed inhaler treatment was $59(89.4 \%)$ while $7(10.6 \%)$ patients reported that they used their inhalers irregularly. There was no statistically significant difference in terms of age, gender, education level, smoking, diagnosis, and duration of disease between adherents and non-adherents according to the patient's own statement. According to the statements of their relatives, 17 (28.8\%) of 59 patients who stated that they used the prescribed inhaler treatment regularly used their treatment irregularly. Conclusion The discrepancy determined between the statements given by the patients and their relatives about the adherence of the patients in our study revealed a serious problem in the assessment of adherence according to the patients' statement. In this context, an approach that includes patient relatives in the assessment of adherence to inhaler therapy may help to evaluate adherence more accurately and to increase patient adherence.
\end{abstract}

\section{Introduction}

The desired control levels cannot be achieved in patients with obstructive lung diseases despite the frequent use of inhaled corticosteroid and long-acting beta agonist combination (ICS / LABA). Insufficient adherence, incorrect inhaler technique, and refractory disease are the most important causes of uncontrolled obstructive lung diseases. Strict patient adherence to inhaler therapies in asthma and chronic obstructive lung disease (COPD), together with correct application of the inhaler technique, are the two most critical issues in obtaining the desired treatment results $[1,2]$. However, studies clearly show that adherence with inhaler treatments is insufficient in patients with asthma and COPD [3,4].

In a study conducted with difficult asthmatics, it was found that low adherence was more common in women and was associated with repeated hospitalizations as well as frequent use of nebulized bronchodilator medication [3]. A retrospective cohort study examining 11,708 COPD patients in China showed that using ICS / LABA combination maintenance therapy with high adherence levels resulted in $34.8 \%$ less hospitalizations due to exacerbations compared to those using this treatment low adherence [4].

Non-adherence is associated with many poor clinical outcomes, and non-adherence determination is crucial for optimal disease management. In the study of Murphy et al. patients with poor ICS adherence had lower post-bronchodilator forced expiratory volume in 1 second $\left(\mathrm{FEV}_{1}\right)$ values and higher sputum eosinophils compared to those with adequate ICS adherence. There was no statistically significant difference between these two groups in terms of age, gender, ethnicity, smoking history, and salvage oral prednisolone therapy. 
However, it has been shown that patients with poor adherence with ICS treatment are mostly ventilated [5]. The findings revealed by Murphy et al. leave us face to face with the important reality of correct assessment of adherence in asthmatics. Because if the adherence is not evaluated correctly, it can lead to unnecessary additions of drugs to the treatment of patients and even to treatment with biological agents that are very popular today.

Today there is no method that accurately evaluates adherence [6]. However, rational studies are planned on this subject and it is obvious that there will be a very important paradigm change in the very near future [7]. Most research focuses on drug adherence. However, there is no uniformity in the terminology used to describe adherence. In the study of Vrijens et al., it was determined through a literature review that more than ten different terms had been used to describe appropriate use of medication [8].

Adherence, actually, encompasses a range of health-related behaviors that go beyond taking prescription drugs. World Health Organization (WHO) defines adherence as the extent to which the patient follows medical instructions. However the organization emphasizes some very important points related to this definition. First, the termmedical is considered insufficient to describe the various interventions used to treat chronic diseases. Second, the terminstructions implies that the patient is a passive recipient who can receive expert advice as opposed to an active collaborator in the treatment process. Moreover, in its report WHO underlines that adherence is a set of behaviors. Seeking medical help, filling prescriptions, taking medications properly, attending follow-up appointments, self-management of the disease, smoking, unhealthy diet, and physical activity are all examples of therapeutic behavior [9]. A more robust evidence-based approach is needed to assess adherence. If a systematic approach and standardization for measuring and reporting compliance can be developed, patient follow-up can be made better and the value and generalizability of research can increase [10].

In this study, we aimed to ask the patients with obstructive lung disease and their relatives about the medication adherence of the patients and to evaluate the consistency of the information they provide. In addition, we aimed to compare the demographic, smoking-related, and clinical characteristics of patients who stated that they were adherent and non-adherent to inhaler therapy.

\section{Methods}

A cross-sectional study was conducted between January and March 2020 in the allergy and pulmonology outpatient clinics of a tertiary chest diseases hospital, where patients with asthma and COPD were regularly followed up. Study was conducted in patients with a diagnosis of asthma or COPD who had been followed for at least one year and whose treatment was arranged as maintenance inhaler therapy were included in the study. Patients who attended the scheduled follow-up visit with a relative living in the same house with the patient were included in the study if they volunteered to participate.

In order to question the adherence of the patients who agreed to participate in the study, the patient and his / her relative were taken to different rooms and interviewed by Drs. T.T. and A.F. who are the investigators of the study. The patients and their relatives living in the same home with the patient were asked whether the patient used the prescribed inhaler treatment regularly in face-to-face meetings.

The patients were asked about the usage patterns of their inhaler treatments. They were asked how many days per week, how many times per day, and how many puffs each time they take their controller inhaler in the last 4 weeks. With the help of this inquiry, it was evaluated whether the patients used the inhalers, which were prescribed by their physicians and recommended to be used regularly, every day as recommended. Those who were understood to use the drug regularly every day on the appropriate schedule were recorded as adherents according to their own statements. The relatives who live in the same house with the patient independently were asked to make the same assessment and to report whether the patient used inhaler treatment regularly. Patients who were reported by their relatives to use their medication regularly every day were accepted as adherents according to the statement of the patient's relative. If the patient's relative reported that the patient only uses his/her inhaler when it comes to mind or does not use it at all then the patient was accepted as non-adherent according to relative's declaration. Age, gender, education level, 
smoking, diagnosis and duration of disease were compared between adherents and non-adherents.

Continuous variables were expressed as mean \pm standard deviation (SD) and categorical variables as numbers (percentages). The normal distribution of continuous variables was evaluated by the Shapiro-Wilk test, normality test, and Q-Q graphs. Any differences between groups were evaluated using Student's t-test for continuous variables and chi-square test for categorical variables. All statistical tests were two-sided, and a p-value $<0.05$ was considered statistically significant. The analyses were carried out using SPSS (Statistical Package for the Social Sciences, IBM Corp., Armonk, NY, USA) version 22.

The study was approved by the Ethics Committee of Keçiören Training and Research Hospital Clinical Research Ethics Committee (08 January 2020/2012- KAEK-15/2040). Informed consent was received from all participants.

\section{Results}

A total of 66 patients, 33 women and 33 men, were included in the study. While 42 of these patients were followed up with a diagnosis of COPD, 24 of them were followed up with a diagnosis of asthma. The mean age of the patients was $63.1 \pm 13.3$ years. Disease duration was $9.0 \pm 8.4$ in patients with COPD, while it was $13.8 \pm 12.6$ in patients with asthma. The characteristics of the study group are presented in Table 1.

According to the patients' own statements, the number of patients who regularly used the prescribed inhaler treatment was $59(89.4 \%)$ while the number of patients who said they used it irregularly was only $7(10.6 \%)$. According to the statements of their relatives, 17 (28.8\%) of 59 patients who stated that they used the prescribed inhaler treatment regularly used their treatment irregularly (Table 2). There was no statistically significant difference in terms of age, gender, education level, smoking, diagnosis and duration of disease between adherents and non-adherents according to the patient's own statement (Table 3). Subjects who stated that they used inhaler treatment regularly were grouped into two according to their relatives' statements; 1 ) patients who are reported to use the treatment regularly by their relatives 2) patients whose relatives stated that they did not use their treatment regularly. It was seen that duration of obstructive lung disease was $12.1 \pm 11.0$ years versus $6.9 \pm 6.9$ years in the two groups respectively $(\mathrm{p}=.045)$. Other parameters including gender distribution, smoking status, diagnosis of asthma or COPD, educational level, and mean age (years) were not statistically different between the two groups (Table 4).

\section{Discussion}

With the introduction of therapeutic aerosols in 1956 in the treatment of respiratory diseases, problems related to treatment began to occur within a few months [11]. International asthma and COPD guidelines strongly recommend evaluating the inhaler technique and adherence to the prescribed dosage regimen before concluding that current therapy is inadequate $[1,2]$. Inadequate medication adherence is common and associated with poor disease control and outcomes. Real-life data in asthma show that treatment adherence is in the range of 8-70\%. Low inhaler adherence has also been associated with frequent asthma exacerbations [12-17]. In COPD, adherence with medical treatment is between 20-60\%, and low treatment adherence is associated with increased disease mortality $[18,19]$. Similar to other countries, also in Turkey, level of adherence is not at desired levels in asthma and COPD patients and is associated with uncontrolled disease $[20,21]$.

Currently, there is no perfect method for determining adherence to inhaler treatments in patients with obstructive lung diseases. Methods recommended for the follow-up of adherence in the management of asthmatic patients are direct biochemical measurement of the drug in blood or other body fluids, clinician judgment, patient self-report, prescription refill data, and electronic monitoring devices. Direct biochemical measurement can evaluate actual uptake, but it is costly, invasive, and only provides a point estimate of compliance. Clinician judgment and patient self-report can provide actual insight into non-adherent behavior, if regular face-to-face meetings and effective patient-clinician communication takes ongoing action. Longitudinal adherence measurement with prescription refills provides a continuous and remotely accessible alternative. Electronic monitors are objective, but widespread use has been limited by different monitors being needed 
for each device type. Each of the available methods has its own strengths, but none of the methods are specifically designed for the management of asthma non-adherence [6].

With this study it was seen that adherence assessment based only on the patient statements is a troublesome method. According to the study results, $89.4 \%$ of patients with obstructive lung disease participating in the study stated that they are adherent to the prescribed inhaler therapy. However, $28.8 \%$ of the patients who stated that they used the prescribed inhaler treatment regularly were using it irregularly according to the statements of their relatives. It was also observed in the study that, relatives of some of the patients who stated that they did not use the drug regularly reported that the patient is adherent to inhaler therapy. Therefore, the discrepancy between the statements given by the patients and their relatives in our study revealed a serious problem in assessment of adherence based solely on the patient's statement. In this context, we think that patient relatives may be involved in the clinical judgment of adherence. This approach may help us both to evaluate adherence more accurately and to increase patient adherence. In this context, our study offers a different perspective.

Bender et al. investigated adherence and persistence for 12 months from the date of the first fluticasone propionate / salmeterol combination prescription in 5504 patients with COPD. Adherence to inhaler treatment was determined as $22.2 \%$ in that study. This pharmacy database study showed that drug adherence level was at a significantly low level [22]. Smart inhaler devices, also known as e-inhalers, containing sensors in an e-module, can help us in the following years [7]. However, it is a reality that they cannot be equally helpful for every type of adherence, especially the intelligent non-adherence type [6]. Therefore, regular and high quality communication between the patient and the physician is very important. In this regard involving the family members living in the same house may be beneficial. Our results emphasize that when the relatives of patients who report being adherent are questioned, it may turn out that patients are adherent.

Sulaiman et al. conducted an actual adherence study in patients with COPD in 2017, evaluating both intentional and unintentional non-adherence. Among 244 COPD patients discharged from the hospital with predicted FEV1 values below 80\%, 179 patients with available data were evaluated within 30 days of discharge. The mean adherence was found to be $59.8 \%$. The major factors determining adherence were poor lung function and impairment in cognitive function [23]. In a prospective, observational cohort study conducted by Cushen et al in 2018, discharged COPD patients were followed with a smart inhaler for adherence. In this study, four different clusters of adherence behaviour were defined. In that study, it was observed that patients with irregular use and poor inhaler technique had the highest mortality rate, and patients with good inhaler technique but who used their treatment irregularly had the highest general healthcare use. The study of Cushen et al. emphasizes the importance of detailed assessment of medication adherence in COPD [24]. In 2020, O'Dwyer et al. reported that digital technologies are valuable to quantify adherence and have clinical value in promoting adherence through biofeedback in patients with obstructive lung diseases [25]. However, there are relatively few digital technologies and smart inhalers in use all over the world. Therefore, the best way to evaluate adherence is to have good communication with the patient and to check drug records in the pharmacy system. By referring to the information of family members living in the same house, success in objectively evaluating adherence will be increased.

One of the important limitations of our study is the small number of patients. However, the number of patients who applied to the outpatient visit with a relative living in the same house is very low. The second limitation of our study is that the relationship between adherence and disease control was not evaluated because it was not included in the design of the study.

As a conclusion, it is a fact that rate of adherence to inhalers is low in real life. Attempts are being made to improve adherence rates, but there is still a long way to go. For the follow-up of adherence clinician judgment and patient self-reports. Adding the information of patients' relatives to the use of patient self-reports can increase the power of clinician's judgment in the follow-up of medication adherence.

Acknowledgements: FA and KA had full access to all of the data in the study and takes responsibility for the integrity of the data and the accuracy of the data analysis. FA and KA constructed hypothesis 
for research, FA, KA, TT and AF contributed substantially to the study design, TT, and AF contributed substantially to data collection, FA, and KA performed data analysis and interpretation. FA, KA, TT, and AF substantially contributed to the writing of the manuscript. FA, KA, TT and AF approved final manuscript.

Conflict of Interest: Authors have no conflicts of interest regarding the submitted work.

Funding information: No funding was received for the study.

Dr. Kurtuluş Aksu reports personal fees from Novartis, personal fees from Astra Zeneca, personal fees from Chiesi, personal fees from Sandoz, personal fees from GlaxoSmithKline, personal fees from İbrahim Etem, personal fees from Abdi İbrahim, outside the submitted work.

Dr. Funda Aksu, Dr. Tuğba Tezvergil and Dr. Ali Fırıncıŏluları has nothing to disclose for three-year period prior to the date of submission.

\section{Availability of data and material}

The dataset used and/or analyzed during the present study is available on reasonable request.

\section{REFERENCES}

1. Global Initiative for Asthma. Global Strategy for Asthma Management and Prevention, 2020. Available from:www.ginasthma.org. Accessed August 25, 2020.

2. Global strategy for the diagnosis, management, and prevention of chronic obstructive pulmonary disease (2020 report). Available from: goldcopd.org. Accessed August 25, 2020.

3. Gamble J, Stevenson M, McClean E, Heaney LG. The prevalence of nonadherence in difficult asthma. Am J Respir Crit Care Med. 2009;180(9):817-822.

4. Chen R, Gao Y, Wang H, Shang H, Xuan J. Association Between Adherence to Maintenance Medication in Patients with COPD and Acute Exacerbation Occurrence and Cost in China: A Retrospective Cohort Database Study. Int J Chron Obstruct Pulmon Dis. 2020;15:963-971.

5. Murphy A, Proeschel A, Linnett M, Bradding P, Green R. Identifying non-adherence with asthma medication and the relationship to clinical outcomes amongst adults with difficult-to-control asthma. Allergy 65 (Suppl. 92): 1-77.

6. van Boven JF, Trappenburg JC, van der Molen T, Chavannes NH. Towards tailored and targeted adherence assessment to optimise asthma management. NPJ Prim Care Respir Med. 2015;25:15046.

7. Mokoka MC, Lombard L, MacHale EM, et al. In patients with severe uncontrolled asthma, does knowledge of adherence and inhaler technique using electronic monitoring improve clinical decision making? A protocol for a randomised controlled trial. BMJ Open. 2017;7(6):e015367.

8. Vrijens B, De Geest S, Hughes DA, et al. A new taxonomy for describing and defining adherence to medications. Br J Clin Pharmacol. 2012;73(5):691-705.

9. World Health Organization. (2003). Adherence to long-term therapies: evidence for action / [edited by Eduardo Sabate]. World Health Organization. https://apps.who.int/iris/handle/10665/42682. Accessed September 18, 2020.

10. Tibble H, Flook M, Sheikh A, et al. Measuring and reporting treatment adherence: What can we learn by comparing two respiratory conditions? Br J Clin Pharmacol. 2020;10.1111/bcp.14458.

11. Freedman T. Medihaler therapy for bronchial asthma; a new type of aerosol therapy. Postgrad Med. 1956;20(6):667-673.

12. Melani AS, Bonavia M, Cilenti V, et al. Inhaler mishandling remains common in real life and is associated with reduced disease control. Respir Med. 2011;105(6):930-938. 
13. Murphy AC, Proeschal A, Brightling CE, et al. The relationship between clinical outcomes and medication adherence in difficult-to-control asthma. Thorax. 2012;67(8):751-753.

14. Engelkes M, Janssens HM, de Jongste JC, Sturkenboom MC, Verhamme KM. Medication adherence and the risk of severe asthma exacerbations: a systematic review. Eur Respir J. 2015;45(2):396-407.

15. Breekveldt-Postma NS, Koerselman J, Erkens JA, et al. Treatment with inhaled corticosteroids in asthma is too often discontinued. Pharmacoepidemiol Drug Saf. 2008;17(4):411-422.

16. Rand CS, Wise RA. Measuring adherence to asthma medication regimens. Am J Respir Crit Care Med. 1994;149(2 Pt 2):S69-S78.

17. Horne R. Compliance, adherence, and concordance: implications for asthma treatment. Chest. 2006;130(1 Suppl):65S-72S.

18. Moran C, Doyle F, Sulaiman I, et al. The INCATM (Inhaler Compliance AssessmentTM): A comparison with established measures of adherence [published correction appears in Psychol Health. 2017 Oct;32(10):i]. Psychol Health. 2017;32(10):1266-1287.

19. Vestbo J, Anderson JA, Calverley PM, et al. Adherence to inhaled therapy, mortality and hospital admission in COPD. Thorax. 2009;64(11):939-943.

20. Gemicioglu B, Bayram H, Cimrin A, et al. Asthma control and adherence in newly diagnosed young and elderly adult patients with asthma in Turkey. J Asthma. 2019;56(5):553-561.

21. Kokturk N, Polatli M, Oguzulgen IK, et al. Adherence to COPD treatment in Turkey and Saudi Arabia: results of the ADCARE study. Int J Chron Obstruct Pulmon Dis. 2018;13:1377-1388.

22. Bender BG, Pedan A, Varasteh LT. Adherence and persistence with fluticasone propionate/salmeterol combination therapy. J Allergy Clin Immunol. 2006;118(4):899-904.

23. Sulaiman I, Cushen B, Greene G, et al. Objective Assessment of Adherence to Inhalers by Patients with Chronic Obstructive Pulmonary Disease. Am J Respir Crit Care Med. 2017;195(10):1333-1343.

24. Cushen B, Sulaiman I, Greene G, et al. The Clinical Impact of Different Adherence Behaviors in Patients with Severe Chronic Obstructive Pulmonary Disease. Am J Respir Crit Care Med. 2018;197(12):1630-1633.

25. O'Dwyer S, Greene G, MacHale E, et al. Personalized Biofeedback on Inhaler Adherence and Technique by Community Pharmacists: A Cluster Randomized Clinical Trial. J Allergy Clin Immunol Pract. 2020;8(2):635-644.

Table 1. Demographic, smoking-related, and clinical characteristics of subjects $(\mathrm{n}=66)$.

\begin{tabular}{ll}
\hline Age (years) (mean \pm SD) & $63.1 \pm 13.3$ \\
\hline Gender & $33(50.0)$ \\
Male & $33(50.0)$ \\
Female & \\
Smoking status & $7(10.6)$ \\
Smoker & $59(89.4)$ \\
Non-smoker & \\
Diagnosis & $24(36.4)$ \\
Asthma & $42(63.6)$ \\
COPD & $10.7 \pm 10.3$ \\
Duration of obstructive lung disease (years) (mean \pm SD) \\
Educational level & $10(15.2)$ \\
İlliterate & $47(71.2)$ \\
Elementary- secondary school &
\end{tabular}




\begin{tabular}{ll}
\hline Age (years) (mean \pm SD) & $63.1 \pm 13.3$ \\
\hline High school- university & $9(13.6)$ \\
Treatment regimen & $22(33.3)$ \\
Maintenance & $29(43.9)$ \\
Maintenance and reliever & $15(22.7)$ \\
Maintenance and reliever and nebulised treatment & \\
Treatment relieving patient's symptoms & $37(56.1)$ \\
Maintenance & $26(39.4)$ \\
Reliever & $3(4.5)$ \\
Both maintenance and reliever & \\
Adherence according to patient's own statement & $59(89.4)$ \\
Adherent & $7(10.6)$ \\
Non-adherent & $21(31.8)$ \\
Adherence according to relative's statement & $45(68.2)$ \\
Adherent & Non-adherent
\end{tabular}

Data are given as n (\%), unless otherwise stated. COPD: chronic obstructive pulmonary disease, SD: standard deviation.

Table 2. Adherence according to patients' and their relatives' statement $(n=66)$.

\begin{tabular}{lll}
\hline & $\begin{array}{l}\text { Adherent according to } \\
\text { patient's own statement } \\
(\mathrm{n}=59)\end{array}$ & $\begin{array}{l}\text { Non-adherent according to } \\
\text { patient's own statement }(\mathrm{n}=7)\end{array}$ \\
\hline $\begin{array}{l}\text { Adherent according to } \\
\text { relative's statement }(\mathrm{n}=45)\end{array}$ & $42(71.2)$ & $3(42.9)$ \\
$\begin{array}{l}\text { Non-adherent according to } \\
\text { relative's statement }(\mathrm{n}=21)\end{array}$ & $17(28.8)$ & $4(57.1)$ \\
\hline
\end{tabular}

Data are given as n (\%).

Table 3. Demographic, smoking-related, and clinical characteristics of adherent and nonadherent patients according to their own statements $(n=66)$.

\begin{tabular}{|c|c|c|c|}
\hline & $\begin{array}{l}\text { Adherent according to } \\
\text { patient's own } \\
\text { statement }(n=59)\end{array}$ & $\begin{array}{l}\text { Non-adherent } \\
\text { according to patient's } \\
\text { own statement }(n=7)\end{array}$ & $\mathrm{p}$ \\
\hline $\begin{array}{l}\text { Age (years) (mean } \\
\pm \mathrm{SD})\end{array}$ & $62.6 \pm 13.2$ & $67.0 \pm 14.6$ & .525 \\
\hline Gender Male Female & $28(47.5) 31(52.5)$ & $5(71.4) 2(28.6)$ & .427 \\
\hline $\begin{array}{l}\text { Smoking Current } \\
\text { smoker Non-smoker }\end{array}$ & $4(6.8) 55(93.2)$ & $2(28.6) 5(71.4)$ & .118 \\
\hline $\begin{array}{l}\text { Diagnosis Asthma } \\
\text { COPD }\end{array}$ & $22(37.3) 37(62.7)$ & $2(28.6) 5(71.4)$ & 1.000 \\
\hline $\begin{array}{l}\text { Duration of } \\
\text { obstructive lung } \\
\text { disease (years) } \\
(\text { mean } \pm \text { SD) }\end{array}$ & $10.6 \pm 10.2$ & $11.9 \pm 11.4$ & .859 \\
\hline
\end{tabular}




\begin{tabular}{llll}
\hline & $\begin{array}{l}\text { Adherent according to } \\
\text { patient's own } \\
\text { statement }(\mathbf{n}=\mathbf{5 9})\end{array}$ & $\begin{array}{l}\text { Non-adherent } \\
\text { according to patient's } \\
\text { own statement }(\mathbf{n}=\mathbf{7})\end{array}$ & p \\
\hline $\begin{array}{l}\text { Educational level } \\
\begin{array}{l}\text { Illiterate Elementary- } \\
\text { secondary school High } \\
\text { school- university }\end{array}\end{array}$ & $9(15.3) 42(71.2) 8(13.6)$ & $1(14.3) 5(71.4) 1(14.3)$ & .997 \\
\hline
\end{tabular}

Data are given as n (\%), unless otherwise stated. COPD: chronic obstructive pulmonary disease, SD: standard deviation.

Table 4. Comparison of demographic, smoking-related, and clinical characteristics of adherent and non-adherent patients according to their relatives among the patients who stated that they used the inhaler therapy regularly $(\mathrm{n}=59)$

\begin{tabular}{|c|c|c|c|}
\hline & $\begin{array}{l}\text { Adherent patients } \\
\text { according to their } \\
\text { relatives' statement } \\
(n=42)\end{array}$ & $\begin{array}{l}\text { Non-adherent patients } \\
\text { according to their } \\
\text { relatives' statement } \\
(\mathbf{n}=17)\end{array}$ & $\mathrm{p}$ \\
\hline $\begin{array}{l}\text { Age (years) (mean } \\
\pm \mathrm{SD})\end{array}$ & $62.7 \pm 13.8$ & $62.4 \pm 12.1$ & .795 \\
\hline Gender Male Female & $20(71.4) 22(71.0)$ & $8(28.6) 9(29.0)$ & .969 \\
\hline $\begin{array}{l}\text { Smoking Current } \\
\text { smoker Non-smoker }\end{array}$ & $3(75.0) 39(70.9)$ & $1(25.0) 16(29.1)$ & 1.000 \\
\hline $\begin{array}{l}\text { Diagnosis Asthma } \\
\text { COPD }\end{array}$ & $17(77.3) 25(67.6)$ & $5(22.7) 12(32.4)$ & .426 \\
\hline $\begin{array}{l}\text { Duration of } \\
\text { obstructive lung } \\
\text { disease (years) } \\
(\text { mean } \pm \text { SD) }\end{array}$ & $12.1 \pm 11.0$ & $6.9 \pm 6.9$ & .045 \\
\hline $\begin{array}{l}\text { Educational level } \\
\text { Illiterate Elementary- } \\
\text { secondary school High } \\
\text { school- university }\end{array}$ & $5(55.6) 31(73.8) 6(75.0)$ & $4(44.4) 11(26.2) 2(25.0)$ & .530 \\
\hline
\end{tabular}

Data are given as n (\%), unless otherwise stated. COPD: chronic obstructive pulmonary disease, SD: standard deviation. 